\title{
Coverage of Female Spouses of Presidential Candidates in Online News
}

\author{
Yvonne Dedzo \\ Department Of Communication and Media Studies, University of Education, Winneba \\ Andy Ofori-Birikorang \\ Department Of Communication and Media Studies, University of Education, Winneba
}

\begin{abstract}
This study examines the coverage in online news portals of female spouses of presidential candidates during the campaign prior to Ghana's 2016 general elections. The study sought to uncover the ways in which female spouses of presidential candidates of the 2016 general elections in Ghana were portrayed through the lens of framing, gender and social constructionism theories. A total of 1252 paragraphs were analysed from online news portals of Citifmonline, Myjoyonline, Ghanaweb, Peacefmonline, Graphiconline and Pulsegh over a period of four months from August 2016 to November 2016 using qualitative research approach. Through content analysis, the findings showed that the coverage of the female spouses was predominantly positive and gendered. The female spouses were framed as: active in politics and policy discourses; assertive; and, motivational on issues on the campaign trail. The study concludes that the media gave the female spouses adequate coverage in terms of quantity and quality. However, the coverage reflected elements of gender as a constructed social norm or reality. Finally, contrary to what is dominant in the literature on gender representations in the media, the female spouses were not presented negatively neither were the media insensitive in their reportage. They were portrayed as subverting the traditional gender roles or, on few occasions, affirming them.
\end{abstract}

Keywords: online news portals, female spouses of presidential candidates, framing, social constructionism, gender, elections in Ghana

DOI: $10.7176 / \mathrm{NMMC} / 94-02$

Publication date: December $31^{\text {st }} 2020$

\section{Introduction}

A new trend has emerged regarding the rate and level at which spouses of presidential candidates participate in campaigns leading to elections. Previously, female spouses of presidential candidates fulfilled the inherent escort role played by spouses of presidential candidates. This role makes them visible rather than heard (Zeldes, 2009). In the campaign leading to the 2016 general elections in Ghana for instance, the spouses of the presidential candidates of the two major political parties, the New Patriotic Party (NPP) and National Democratic Congress (NDC), in addition to their escort role, actively campaigned for their husbands to be voted into power.

Evidently, the Ghanaian media did not relent on disseminating the novel role these spouses played during the campaign. The women were portrayed as very active in every major event in the various media outlets including print, broadcast and online. Considering the contributions of these women and how the media adeptly projected them into limelight, this study investigates the coverage given to them in online news portals owing to the fact the latter, as an aspect of new media, has diffused remarkably widely among consumers of news in Ghana.

\section{Rationale}

While a lot of studies have been conducted on media coverage of issues pertaining to general elections (Azanu, 2012; Oyesomi \&Oyero, 2012; Rek \& Murphy, 2015), few have actually focused on how the media cover female spouses of presidential candidates on online news portals during presidential campaigns. In view of this lacuna in the literature, this study contends that given the fact the female spouses played tremendous roles to help communicate their husbands' messages to voters during the campaign period, it has become imperative to explore media coverage of the female spouses of the presidential candidates. It is also imperative to assert that while numerous studies exist on the media coverage of elections few studies on online platforms exist. Even most importantly is our contention that no studies exist on the coverage in online news portals of the spouses of presidential candidates and the roles they played in the elections during the campaign season. Therefore, this study through a qualitative methodology as well as social constructionism, framing and gender theories, investigates how six purposively selected online news portals framed the female spouses of presidential candidates prior to the 2016 general elections in Ghana. The study further examined gendered and dominant frames used to cover the spouses.

\section{Gender Theory}

Whereas sex and gender are argued to be biologically determined, gender is seen by scholars like Kessler and 
Mckenner (1978) and Lorber (1994) as a social construction. Hence, gender becomes a contextual, socially constructed means of assigning roles and norms to given sex categories (Handrahan, 2004). Janus (2008) also views gender as the socially constructed roles, behaviours, activities and attributes that a particular society considers appropriate for men and women. Succinctly, society expects that males and females adopt, believe and fulfill specific gender roles and stereotypes that have been established (Wilde, 2007). Men and women, sometimes, are physically segregated on the basis of the assumed differences in their bodies, capabilities, and interests (Lorber, 1993) as well as the widely shared beliefs about what activities are normal and appropriate for each gender (Westbrook \& Schilt, 2013) . Therefore, girls are taught to do household chores whereas boys learn to perform production tasks (Crabb \& Bielawski, 1994). Moreover, Braimah (2015) avers that social constructions influence men and women to behave in ways that conform to the stereotype of masculinity (aggressive, independent, authoritative and controlling) and femininity (emotional, nurturer, cooperative and dependent).

Furthermore, gender is not something we are but something we do (West \& Zimmerman, 1987 as cited in Deutsch, 2007). It is the manifestation of process and performance of what is considered to be ideal or norm for men and women in the society. Deutsch (2007) avers that people act in accordance with what has been prescribed as masculine or feminine behaviour by the society. However, gender is not culturally specific because the ideal behaviour by men and women vary across borders (Deutsch, 2007). Butler (1999) concludes that gender is performative but the individual is not the subject that controls the performance, rather the performance of the individual is controlled by norms and institutions in society.

\section{Social Constructionism}

Berger and Luckmann (1991) describe social construction as how reality is socially constructed and that the sociology of knowledge must analyse the processes in which this occurs. In other words, it is about how the cache of shared knowledge created through social interaction constructs the reality we live in, since it shapes our thoughts and behaviours. They further state that the specific accumulations of "reality" and "knowledge" pertain to specific social contexts, and the individuals, by behaving according to their shared knowledge maintain and reinforce the ongoing production of the shared knowledge.

Iwashita (2003) sees social constructionism as the principle that social and cultural phenomena and individuals are produced and reproduced through historically and culturally situated interactions of people and human activities in society. Therefore, things do not occur in vacuum in the world but constructed, negotiated, formed and fashioned by human beings through their social interaction and practices. Again, the author is of the conviction that a great number of people's experience and sense of realities and the social world in which they live, are to be envisaged of as socially constructed. Consequently, identities that were thought to be given naturally are also socially and culturally created, maintained, modified or even recreated, whether as individual, group, place, landscape or nation-state, through human activities. This is what Ofori-Birikorang (2009) describes as "complex interaction" through which "individuals become active participants in the social process and through such engagement construct their own social realities" (p. 32).

Carroll (2008) and Iwashita (2003) believe that social construction as a social product is always a process; it can, therefore, change over time and in different cultures or societies. Again, social reality is constructed by people through language and discourse as well as through the several agents of socialisation - home, school, churches, peers, business, military and the mass media ipso facto is perceived to be the most dominant.

\section{Framing Theory}

Like any other concept or theory, framing has been explicated differently by scholars since its introduction by Goffman in 1974. In its basic form, framing theory suggests that by framing issues in particular ways, the media can play a central role in not only what issues the public should be made aware of, but also how these issues are perceived. Entman (1993) also avers that the process of framing involves selecting some aspects of a text and making them salient in order to "promote a particular problem definition, causal interpretation, moral evaluation (and/or) treatment recommendation for the item described" (p. 52). Ofori-Birikorang $(2009 ; 2018)$ also holds a similar view that the media in performing their function have been noted to consciously or unconsciously enact a pattern of reportage that involves active selection of some issues and making them more salient. Chong and Druckman (2007) view framing as the process by which people develop a particular view of an issue or reorient their thinking about an issue based on how they are presented to them.

Entman (1993) notes that frames can be located in the communicator, the text, the receiver or the culture in which they become embedded. de Vreese (2005) is of the opinion that the components of framing identified by Entman (1993) are integral to the process of framing which in itself consists of distinct stages: frame-building, frame-setting, and individual and societal level consequences of framing. Frames in the news may affect learning, interpretation, and evaluation of issues and events. The consequences of framing can be conceived on the individual and the societal level. An individual level consequence may be the altered attitudes about an issue based on exposure to certain frames. On the societal level, frames may contribute to shaping social level processes such 
as political socialisation, decision-making, and collective actions.

Ryan (2013) equally postulates that frames are made of two major types: frames in communication and frames in thought. The former refers to the use of "words, images, phrases and presentation styles" by a speaker such as a media outlet to relay information about an issue or event to an audience while the latter refers to "an individual's understanding of a situation" (p.15). Thus, frames in communication tend to shape frames in thought, known as framing effect. Similarly, Kiwanuka-Tondo, Albada and Payton (2012) see framing on two levels: as a macro construct- which refers to the manner of presentation that media organisations use to present information; and as a micro construct- which also describes how people use the information and presentation modes when forming impressions (p. 362). Scheufele and Tewksbury (2007) substantiate the above assertion by stating that frames used by the media as macro-constructs need to diminish the complicatedness of the issues and to accustom them to the needs and constraints of the media and the audiences as well as to the interpretive schemas they were used to. Once in the minds of individuals, frames become micro-constructs that allow audiences to use the received information to form their own impressions and images of the world.

It is observed that the general characteristic that runs through the above definitions of framing is the fact that there is the concept of selection and salience which, according to Gamson and Modigliani (1989), does not rely on facts alone and has no meaning of their own but it is only through being placed in some context through emphasis or focus as part of a frame that the facts take on the cloak of relevance. This study, therefore, seeks to find out which aspects of reality (social construct) were used as frames in the coverage of the female spouses of the presidential candidates during the campaign prior to 2016 general election.

\section{Methodology}

This study was approached qualitatively since it was conducted in the natural or real life setting where the news articles that covered real occurrences were analysed and interpreted without any attempt to make alterations to the data (Denzin \& Lincoln, 2007). Sampling was purposively done based on some set criteria. The sample covered the female spouses of the presidential candidates and their running mates. The two leading political parties in Ghana: the New Patriotic Party (NPP) and the National Democratic Congress (NDC) (www.globalsecurity.org) were selected. The spouses included Rebecca Akufo-Addo (wife of Nana AkufoAddo the then presidential candidate of the NPP); Samira Bawumia (wife of Mahamudu Bawumia, the then running mate of the presidential candidate of the NPP); Lordina Mahama (wife of John Dramani Mahama, the then presidential candidate of the NDC) and Matilda Amissah-Arthur (wife of Paa Kwesi Bekoe Amissah-Arthur, the then running mate of the presidential candidate of the NDC). The study covered a four-month period- from September to December, 2016. This specific time frame was chosen because it was the time that the campaign towards general elections was at its peak (Amevor, 2014). In addition, it was during this time that most of the female spouses of the presidential aspirants actively played a leading campaigning role on the campaign trail across the country.

Six online news portals:ghanaweb.com, myjoyonline.com, pulse.gh.com, peacefmonline.com, citifm.com and graphicgh.com were chosen because they were favourably ranked among the first ten online news portals in Ghana from GeoPoll Media Measurement Report, 2018 (https://www.geopoll.com) and Top sites in Ghana, (2016).

Document analysis was employed as the method by which data was collected. The unit of analysis was 'the paragraph' of each news story selected from the news. In all, 1252 paragraphs from 139 news articles were collected within the four-month period.

After delineating the boundaries and the sample for the study, we did a search of the female spouses of the presidential candidates on the selected online news portals using the world's most popular search engine, Google. The names of all four sampled female spouses were used as keywords during the search. We retrieved all news items published in relation to the keyword being used for the search by concentrating on only the items that appeared under the "news" tab in the Google search engine. After this, another level of search was initiated where news stories that fell within the chosen period of the study were retrieved. The retrieval process did not end there as we transferred all stories that fell within the period of study onto word documents. Data on the word documents were collated and printed for the coding.

Finally, thematic analysis (Braun \& Clarke, 2016) was used to analyse the data since the data was mined through document analysis (Bowen, 2009). At the outset, we engaged the text by doing several readings of every news story sampled so as to gain a general understanding of how the female spouses of the presidential candidates were framed. Descriptive notes were taken at every stage. A close reading of the text was conducted in a more comprehensive manner to identify the issues that were embedded in the data. During this stage we identified the recurrent issues or topics that came up in the coverage and the various issues that emerged were put into categories (Ofori-Birikorang, 2018). These categories were then quantified into a frequency distribution table from which analysis were made. Also, we engaged in active interpretations of the data which is in line with the assertion that, "to understand the media employment of standardized...representations, the reader needs to engage in active interpretations," (Sanders (2000), as cited in Ofori-Birikorang, 2009, p. 90). We went over the stories again grasping the thematic categories. Further, we engaged the texts to gain a deeper interpretation of the themes 
(Lindlof \& Taylor, 2010). This process revealed the deeper meanings that were embedded in the text. Finally, we conducted an analysis of the news stories on the female spouses in relation to the research questions and the theoretical framework.

\section{Findings and Discussion}

This section presents the findings from the data retrieved and analysed using the theories of gender, framing and social constructionism. The findings and discussion are the outcome of investigations conducted into how Ghanaian online news portals framed the female spouses of presidential candidates during the campaign prior to the 2016 general elections. The first section is, however, answered through descriptive statistics which enabled us to present the findings graphically through a table and a bar graph. We presented the cumulative frequency table of the frames that dominated in the coverage of the female spouses by the six online news portals. This afforded us the opportunity to assess the prominence given each of the frames. We concluded the first section with a bar graph which gives a pictorial view of the rank of each of the six frames placed.

\section{Dominant Frames on the Spouses of the Presidential Candidates}

This section sought to probe the dominant frames that manifested in the coverage of the spouses. From the coding, close engagement and analysis of the four-month data on the 6 online news portals made up of 139 news stories and 1252 paragraphs, the news frames that emerged include: partisan politics, policy direction, gender, philanthropy, motivation and assertiveness. As part of findings and discussion, each news frame was isolated and discussed to clearly portray how the news portals framed the spouses around the identified issues.

\section{Table 1}

Cumulative frequency distribution table of the dominant frames used to portray spouses of presidential candidates from August 2016 to November 2016.

\begin{tabular}{lll}
\hline Frames & Thematic Categories & Percentages (\%) \\
\hline Partisan Politics & 350 & 28 \\
Policy Direction & 292 & 27 \\
Gender & 264 & 21 \\
Philanthropy & 126 & 10 \\
Motivation & 105 & 8 \\
Assertiveness & 82 & 7 \\
Others & 42 & 3 \\
\hline Total & $\mathbf{1 2 6 1}$ & $\mathbf{1 0 0}$ \\
\hline
\end{tabular}

\section{Partisan Politics}

As can be seen from Table 1 above, the Partisan Politics frame ranked first as it was the prominent theme with 350 out of the 1261 thematic categories representing $28 \%$. This theme includes issues that integrate all processes in relation to governance, politics, leadership, the campaign and rallies. It is not surprising to see the female spouses framed around partisan politics more than the other subjects since the main area of focus during election campaigns is politics. It, therefore, makes sense that its percentage is higher than the other frames. It can also be concluded that this frame challenges the dominant culture that politics is a man's domain or a man's game, with women continuing to be framed as the novelty other, despite their numbers. As a result, the media specificity of providing definitions for events and conditions that resonate with subjects of the social milieu deeply cast in a social construct around the world and specifically Ghana and which further moulds the belief that partisan politics is a no-go-zone for women has been contested in this circumstance (Carroll \& Fox, 2006; Ofori-Birikorang, 2009; Uscinski \& Goren, 2011). This resonates with Edelman's (1993) assertion that the social world is a kaleidoscope of potential realities, any of which can be readily evoked by altering the ways in which observations are framed and categorised. In furtherance, whether consciously or unconsciously, the journalists drew the attention of the electorate to the reality that the female spouses were involved in the party politics. Here is an example to illustrate,

In this year's campaign, both the NDC and NPP have had their women out in full force. The NDC campaign communications is led by a woman. The first lady and the wife of the Vice president were present and spoke at the NDC's manifesto launch in Sunyani. At the launch of the NPP's manifesto, about four women made presentations on various sectors of the economy.

\section{(2016, November 2) Citifmonline}

The above example expresses the idea of a deviation from the status quo. Moreover, adopting the partisan politics news frame introduces audience to a conflict frame which highlights disagreements between the two major political parties and how these female spouses are equally caught in the crossfire. Thus, in a way, issues of controversy and divergence between conflicting parties are also emphasised (de Vreese, 2004). 


\section{Policy Direction}

This frame ranked second out of the six dominant frames that the online news portals used in the discussion of issues regarding the activities of the female spouses of presidential candidates during the election period. It took 292 out of the 1261 thematic categories representing 23\%. Issues such as health care, provision of health facilities, campaign promises, provision of quality education and infrastructure were espoused here. Under the policy news frame, the female spouses acted or functioned as surrogates for their husbands by leading campaign tours, volunteering, and propagating the policies and strategies of their husbands (Zeldes, 2009). Consequently, this news frame made certain issues or polices more salient than others which might have definitely affected the attitudes of the general public or stimulated their attention on the policies since by priming some specific values, facts and issues, audiences would, probably, base their voting decision on the considerations of the relevance of the issues put forth by the two political parties. Subsequently, the interpretation fostered by such campaign environment would then influence the citizenry on which particular party's ideologies to support (de Vreese, 2004). An illustration of this frame is seen below

Mrs. Akufo-Addo said an Akufo-Addo government will implement the Free SHS programme as well as restore allowances for teacher and nurse trainees as promised by her husband. She said, "Let no one deceive you that Nana Akufo-Addo can’t do it."

\section{(2016, October 3) Pulsegh}

The above post typifies the surrogacy role assumed by the spouses. It also displays the trust Rebecca has in her husband as she is framed urging Ghanaians to throw their weight behind Nana Akufo-Addo.

\section{Gender}

This theme placed third and hence takes the median position on the frequency table of the female spouses' news frame narratives. This frame comprises 264 thematic spaces out of the 1261 representing $21 \%$ of the total coverage of the female spouses within the four-month period. It largely consists of discussions that focused on issues of fashion, beauty or physical appearance, spousal frame, feminine attributes and underrepresentation of women. The female spouses were described by their appearances, in manner not negated to mar their public status. Regardless, reductive language was used in framing these female spouses. For instance, in referring to them, references were made to their husbands, "The wife of the Vice President, Mrs. Matilda Amissah-Arthur." Simply put, this media framing emphasises the social reality or norms of what is acceptable in the society. However, from the observation of the data the female spouses, though framed as conforming to some social constructs, did their best to be heard and not only seen even when they were handling issues believed to be in the domain of women. This therefore challenged the Ghanaian social structure where a woman's role and status are recognizably inferior to those of the man in almost all aspects of social, political and economic life (Allah-Mensah, 2005; Okiring, 2013). The following examples reflect the portrayal of a gendered frame:

Ghanaians, especially women, are "really suffering" under the government of President John Mahama, Mrs. Rebecca Akufo-Addo, wife of opposition New Patriotic Party flag bearer Nana Akufo-Addo, has said..." Mrs. Akufo-Addo said women were bearing the harshest brunt of the suffering under the Mahama administration and, therefore, urged them to vote for her husband to come and change things. "If you vote for Akufo-Addo, I'll make sure I also play my role as First Lady to bring prosperity and comfort to our women."

\section{(2016, October 3) Ghanaweb}

The First Lady, Mrs. Lordina Mahama, has re-stated the commitment of the Lordina Foundation to empower women, indicating that, it is a positive step for them to make meaningful contribution to the country's socio-economic development. She said, since its inception, the foundation had empowered a number of women in parts of the country with skills training and presented them with start-up kits to start businesses, while it had also donated educational materials to some schools, as well as constructed ICT centres and dining halls for these institutions.

(2016, October18) Graphiconline

The exemplars reveal how the spouses are framed as women who, even though are vocal and defy the norm of playing the escort role, still focus on female-related issues.

\section{Philanthropy}

The fourth most dominant news frame used by the online news portals to frame the female spouses' sequence of events for the period of inquiry is philanthropy. Framing the women through the philanthropic portrayal took 126 thematic categories which amounted to $10 \%$ of the amount of space used for all the stories. This frame is the lens through which the electorate or general public is provided a scheme of interpretation on the role of the female spouses in the campaign. Theme indicators such as compassion, advocacy, contribution or donation, and the need to share in one another's burdens became appropriated as the expressions or language of the reportage. Therefore, by framing the female spouses as philanthropists, the news sites made a subtle call to the readers to critically 
evaluate what can be expected from them in terms of either money, time or any other necessities that would improve the lives of Ghanaians. This excerpt illustrates the philanthropy news frame:

Mrs. Matilda Amissah-Arthur, the second lady of the Republic of Ghana who was also present, donated medical supplies and equipment to the hospital. She encouraged institutions and individuals to contribute to this worthy course.

\title{
(2016, September 25) Citifmonline
}

Here, the spouses were framed as being committed to alleviating the burden of the underprivileged in the society.

\section{Motivation}

Motivation news frame is the next dominant news frame used in the coverage. For the period under study, 105 thematic spaces representing $8 \%$ of the total coverage on the female spouses was represented through the motivation news frame. This frame portrayed the female spouses as convincing and encouraging the electorate to come out in their numbers and cast their vote. This they did in a way that left no doubt in the minds of the electorate or readers that whatever decision they made about a particular candidate was solely their choice. In addition, they urged the general public to help in building the country by stressing the importance of nation building as a shared responsibility. For instance,

Mrs. Rebecca Akufo-Addo, wife of the standard-bearer of the opposition New Patriotic Party (NPP), has rallied voters to go out to vote on December 07, to bring change and restore the nation to the path of real progress. She said it was important for everybody to recognize that their vote could make a difference and that should be the motivation.

\section{(2016, October 3) Ghanaweb}

\begin{abstract}
Assertiveness
As can be observed from Table 1, the frame of assertiveness is the least dominant news frame used by the media to narrate the stories of the female spouses of presidential candidates. This news frame appeared in 82 thematic spaces representing 7\% to discuss how the women were vocal relating to issues regarding the general election and the development of the country. It is not surprising to see this frame manifest as the less dominant since being assertive for these women is a novel phenomenon. Journalists maximized this opportunity to draw readers' attention to the fact that these women are breaking stereotypical roles. Generally, it was observed that the female spouses were assertive and demonstrated a lot of confidence, a factor which contributed effectively in their involvement in the political game. They were framed as being in the forefront and not as women who were relegated to the backstage to become mere observers. In view of this frame, the public is made to develop a particular view of the issues these women present and probably reorient their position on the issues based on how they are presented to them through such bold female spouses (Chong \& Druckman, 2007; Zeldes, 2009). Here is an illustration from the data:

[Samira] is just what NPP needs to keep the campaign exciting - a woman who is well-liked, gives the best punch lines and unafraid to speak up, especially her critique of President Mahama and his government was on point. So were her descriptions of her husband's boss.
\end{abstract}

(2016, November 3) Peacefmonline

In the excerpt above, Samira is portrayed as a woman who had a lot to contribute to the campaign through her outstanding quality. 
Figure1: Bar graph of the cumulative frequency distribution table of the dominant frames used to portray spouses of presidential candidates from August 2016 to November 2016.

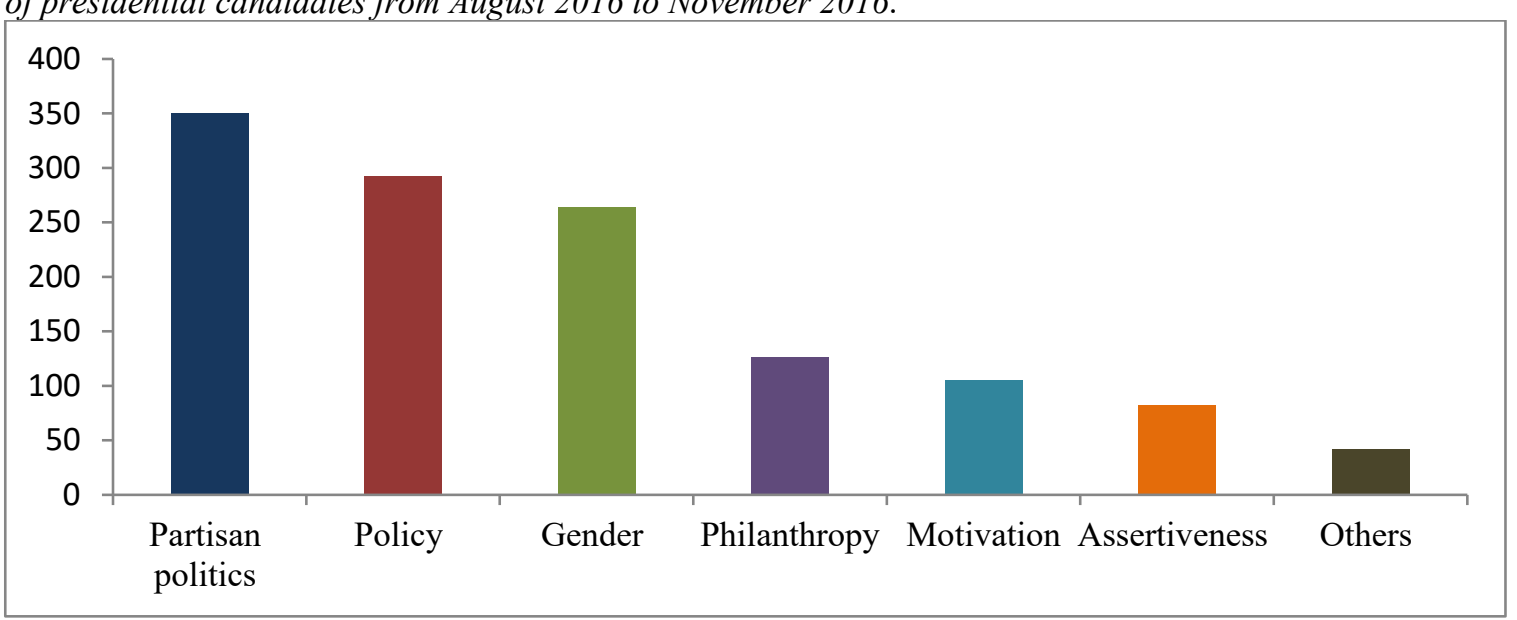

\section{Gendered Portrayals}

Carroll and Fox (2006) reveal that it is a reality that gender is an underlying factor shaping the contours of contemporary elections, thus examining and monitoring the role of gender in the electoral process is important because of concerns over justice and the quality of political representation. Bystrom and Dimitrova (2013) observe that women candidates are much more likely to be discussed in terms of their sex, marital status, and children. Conversely, they also observed that women candidates were more likely to be linked to masculine traits than feminine traits. Confirming the above-mentioned assertion, Atkeson and Krebs (2008) posit that female candidates were more often portrayed as tough and intelligent leaders- qualities that have been assumed to masculine tendencies.

Carroll and Fox (2006) regard gender as malleable, manifesting itself differently at various times and in different contexts in the electoral process. Therefore, the purpose of this section is to assess how gender manifested in the coverage of the female spouses of the presidential candidates on the selected online news portals. This section, however, addresses only five of the themes excluding the frame of gender as the gender frame already implicates the gendering of the frame.

\section{Gender and Partisan Politics}

To Carroll and Fox (2006), the electoral playing field is dominated by men. This means that politics is not the domain of women. The authors explain that,

Politics and elections are most often described in terms of analogies and metaphors drawn from the domains of war and sports: two of the most traditionally masculine domains. Contests for office are often referred to by reporters and political pundits as "battles" requiring the necessary strategy to "harm," "damage," or even "destroy" the opponent. The headquarters of presidential campaigns are called "war rooms" Candidates "attack" their opponents. They raise money for their "war chests." (p. 20).

All these words are pointers to the fact that language plays an important role in assigning roles to men and women. These words obviously confirm the assertion that politics is the domain of men and any woman who enters this domain is deconstructing the social construction of gender. Moreover, as the language used to analyse politics suggests, society's expectations about the qualities, appearance, and behaviour of candidates also are highly gendered. Leaders are expected to be tough, dominant, and assertive - qualities much more associated with masculinity than femininity in American culture and by extension, in most parts of the world (Carroll \& Fox, 2006). Corroboratively, women candidates are potentially stereotyped as typical women - with traits such as soft, gentle, kind, passive, consensus builder, honest. While male candidates are potentially stereotyped as typical men-with traits such as tough, assertive, aggressive, strong leader, knowledgeable, and objective (Atkeson \& Krebs, 2008). These masculine traits have been socially constructed as those expected of political actors.

In the 2016 campaign leading to the elections, the then opposition party, the NPP, interested in regaining political power propagated the message that the then ruling party, the NDC, was unfit to rule the country. On the other hand, the NDC also had launched a campaign aimed at remaining in power. Therefore, both parties had messages crafted to win the electorate over. The communication of these messages to the electorate was spearheaded by party actors including the spouses of the presidential candidates of the parties. In the data for this study, the female spouses were seen engaging in partisan politics on their campaign tours and the media did not hesitate to frame the women around partisan politics. Below is an instance where the Samira Bawumia was framed 
as subverting the stereotypes surrounding the domain of politics by engaging in partisan politics.

Samira Bawumia, wife of the vice presidential candidate of the New Patriotic Party (NPP), Dr. Mahamudu Bawumia, has urged the electorate to vote for the party on December 7 due to its track record in government. She indicated that the NPP was committed to transforming Ghana to improve the lives of the citizens. Mrs Bawumia therefore called on Ghanaians to reject politics of lies and propaganda by the ruling National Democratic Congress (NDC) and vote for the NPP and its flag bearer, Nana Addo Dankwa Akufo-Addo to improve their lives.

\section{(2016, November 26) Peacefmonline}

Alhassan (2012) also suggests that "men's power and their control over the institutions of authority are made manifest in linguistic structures and in recurrent patterns of linguistic behaviour" (p. 23). Moreover, men and women are segregated on the basis of the assumed differences in their bodies, capabilities and interests (Lorber, 1993). The said bases of differentiation facilitate the assignment of roles by society. Kwapong (2009) as cited in Alhassan (2012) emphasises the above statement that through socialisation and cultural orientation, what it means to be a man and woman are deeply rooted in children's earliest experiences and memories, and that the family both male and female members, community members, and peers ensure that cultural norms about gender roles are transferred to male and female children accordingly. In view of the above discussion, the women were seen playing the traditional supportive role of a wife and vouching for their husbands to indicate that politics is not their domain but their husbands are suitable for the role. Below is an example:

I have even seen the wife of the NPP flagbearer, Madam Rebecca Akufo-Addo handing gifts to people in their sick bed in hospitals for instance. I don't think that, really, it was intended to buy votes. We can say that she is campaigning for her husband or marketing her husband.

\section{(2016, November 6) Ghanaweb}

From the extract, Rebecca was seen assisting the husband do things that are inherently embedded in the traditional roles of a woman. More especially, the socially constructed role of women as nurses comes into focus as the visit to the hospital is designated to her and typified the care or nursing duties of women.

\section{Gender and Policy}

Under this frame, the female spouses were framed around policies put forth by the political parties their husbands represent. Bystrom and Dimitrova (2013) have divided policies or what they call issues pertaining to election campaigns into two based on the sex of the political players. They have masculine issues which include "foreign relations, taxes, the economy, big government and terrorism" and feminine issues as "health care, abortion, education, and social security" (p. 1177). Atkeson and Krebs (2008) substantiate that female candidates are perceived as having more typical feminine traits and fewer masculine traits; being more liberal, democratic, and feminist; and, are good at handling issues such as health care, education, and women's rights issues. The online news coverage of the 2016 election campaign provided contradictory positions through the portrayals. This is because, the spouses traversed to the masculine domain to discuss issues like the economy and technology. This traverse into the masculine arena was relatively minimal as the policy frames were predominantly on health, education and social welfare- areas that still fall within the feminine roles. For example,

Speaking to fishermen and fish mongers of the Ledzokuku constituency, in response to news that some of their canoes had been damaged and lost after tidal waves, Mrs. Akufo-Addo promised to mitigate the impact of the disaster upon her return. She reaffirmed the commitment of the NPP to improving the fishing sector and creating related industries in the fishing communities, which will in turn create jobs.

$$
\text { (2016, November 22) Ghanaweb }
$$

In the above example, Rebecca Akufo-Addo was seen traversing to discuss issues relating to employment and the improvement of life of the citizenry through the implementation of policies championed- as arena that has consistently been captured in the literature as the domain of male. Samira Bawumia, for instance, in addressing a group of electorates, delved into how the then ruling party, the NDC, had taken Ghanaians for a ride regarding how the economy of the country was handled. Below is an excerpt:

She [Samira] also chastised the NDC government for spending GHc3.6 million of Ghana's oil revenue on branding some 116 Metro Mass Transit (MMT) buses. Mrs. Bawumia said despite the saga they continue to waste taxpayer's money on giant bill boards and other party paraphernalia across the country. NDC used millions of our monies on bus branding. Ghanaians wailed and advised the NDC to withdraw the contract but they didn't heed to the advice. Currently, NDC flags and Mahama's billboards all over, they've branded every part of Ghana with Mahama's posters.

\section{(2016, October 31) Citifmonline}

Even though the women were mostly seen advocating for policies on health, education, social welfare, Samira, in the above excerpt, broke down economic issues for the electorates' consumption. This debunks Wasburn and Wasburn's (2011) assertion that discussions of political women tend to focus on comparatively trivial subjects 
such as their physical appearance, lifestyle and family rather than their positions on prominent campaign issues.

\section{Gender and Philanthropy}

Women are framed as people who are compassionate, which is an intrinsic female attribute. In what Winfield and Friedman (2003) referred to as the noblesse-oblige frame, the first ladies of the United States of America were framed around charitable works and interests. This frame manifested in this study as the frame of philanthropy. Here, the women were portrayed as those who had the welfare of the less privileged in the society at heart. However, these spouses were framed around feminine issues like, health care and education, caring for orphans and children in their philanthropic activities. This is confirmed in literature as Atkeson and Krebs (2008) aver that women candidates are perceived as being better able to handle the so-called compassion issues such as health care, education, and women's rights issues. Also, the media portrayed the philanthropic gestures of the female spouses as an attempt to win the electorates over to vote for the parties they represented. Peacefmonline even discusses how the then First Lady, Lordina Mahama's humanitarian works served as a leverage for the NDC party in the elections. Here is an excerpt,

First Lady Lordina Mahama whose NGO activities have been strong on the ground is targeting the average population through support especially in the area of health.

\section{(2016, September 16) Peacefmonline}

\section{Gender and Motivation}

Under this frame, we looked at how the women used motivation as a tool to urge the citizenry to vote their husbands into power. Even though these women were calling and appealing to all Ghanaians to come out in their numbers to vote for their husbands, their major target group was women, especially market women, hence they crafted and propagated messages that connected with their target audience. Carroll and Fox (2006) substantiate this skew with the assertion that elections are gendered in the strategies candidates employ in reaching out to women and men in the general public. Candidates, both men and women, strategise on how to present themselves to voters of the same and opposite sexes. To the authors, pollsters and campaign consultants routinely try to figure out the issues or themes that would appeal to women or to men. Therefore, candidates and their strategists design different messages to be delivered to voters based on their gender and other demographics. The female spouses of the NPP presidential and vice presidential candidates, for example, espoused that though the whole country was plunged into economic hardship due to mismanagement and the incompetence of the incumbent government, women and their children were the hardest hit. The female spouses gendered their messages and strategies in reaching out to the general public.

My engagement with our mothers at the Mallam Atta and Mamobi markets revealed deeper understanding of the hardship we are facing than we ordinarily speak of. I formally cut the sod and dedicated a footbridge I constructed for the people of Mamobi and stressed the need to vote massively for the NPP to secure the future of our country.

\section{(2016, September 1) Ghanaweb}

\section{Gender and Assertiveness}

To Affum (1998), gender is a social construct that metamorphoses when transformations occur in society and such changes could either be economic, social or political. This view is substantiated by the changes society has seen in recent times as gender advocacy campaigns have increased in the pursuit of gender parity. The changes in society relative to the deconstruction of the stereotypical gender roles justify the confidence and assertiveness of the female spouses of the presidential candidates during the 2016 campaign.

News stories were published on how vocal and maverick the female spouses were on the campaign tours. They were basically framed as women who subvert and deconstruct the traditional gender roles by exhibiting masculine tendencies or qualities such as bravery, intelligence or as Carroll and Fox (2006) put it, "most often than not we want our leaders to be tough, dominant, and assertive; qualities much more associated with masculinity than femininity" (p. 3). Hence in these instances, the spouses emerged from their subordinate roles to be spokespersons (Zeldes, 2009). For instance, Samira had to endure a lot of criticism for speaking her mind because in the minds of many, she did not embody the stereotypical feminine representation. Therefore, her unconventional approach which is how her actions were perceived during the campaign was not well received. As a result gendered beliefs and gender stratification system that devalue females and femininity was evident in the coverage (Uscinski\& Goren, 2011).

In a variety of situations, men are viewed as superior and more competent while women are viewed as inferior at specific tasks and in general. Gender biases are especially common among males hence it is not surprising that the assertiveness of these female spouses unnerve men. For instance, Ghana's Ambassador to Saudi Arabia, Alhaji Saeed Sinari described Samira as a bad Muslim wife. He said,

If this girl with a mouth like that of crocodile should be offered to me for free to marry, I swear to God I 
would add the dowry to her and throw her back to her parents.

(2016, November 19) Pulsegh

In the same story, the news portal framed Samira as assertive in the concluding sentence as excerpted below:

But Mrs. Bawumia insisted that she was misrepresented and asked the general public to disregard such reports and rather listen to the audio which she believes will vindicate her.

(2016, November 19) Pulsegh

In the above excerpts, it can be inferred that the Ambassador was uncomfortable with the way Samira Bawumia, a Muslim woman was assertive during the campaign period. Additionally, the fact that she was able to defend herself in public, which is a masculine tendency, confirms her courage and unconventional character as a woman. Although Norris and Lovenduski (1995) observe that the supply of female candidates is shaped strongly by ideologies of gender, which lead women to have fewer resources of time and money and lower levels of political ambition and confidence, the female spouses of the presidential candidates have redefined this stance. In recent times, these spouses are being framed by the media as those who have confidence and are not fearful to communicate their beliefs even if such beliefs are conventionally masculine oriented. Additionally, the fact that there is a long-standing pattern of traditional socialisation which associates men with the public and women with the private (Krook, 2010) makes an assertive woman on a campaign tour stand out and it is a strong ground upon which the women were given the needed media attention during the period under study. Peacefmonline, for instance, did a feature on the women representation and participation in the campaign of the two major political parties and concluded by portraying Samira Bawumia and Rebecca Akufo-Addo as articulate and assertive. Below is the extract:

At the last rally, both Samira and Nana Addo's wife, Rebecca spoke. They were both charming, sure, and articulate ... I hope Mrs. Akufo-Addo and Samira will not just be seen but heard if their husbands make it to the presidency. Whatever happens I look forward to hearing more from Samira on the campaign trail, she is compelling and authentic. She is just what NPP needs to keep the campaign exciting - a woman who is well-liked, gives the best punch lines and unafraid to speak up.

\section{(2016, November 3) Peacefmonline}

Moreover, one method that the news media used to motivate people to read about issues is to frame it in such a way that the reader could identify and interpret the stories and events in relation to what they see and hear so that they could make sense of them (Goffman, 1974). Inherently, social actors are aware that politics is not a domain for women in a patriarchal society like Ghana and the media take advantage of this social construct to frame the women around the hard issues to reveal their unconventional nature. In doing this, the media do not relent on reminding the readers and reiterating the fact that the female spouses are still women. In view of this, the online news portals always made it a point to define the women according to what their husbands are. In the social construction theory, gender is thus accomplished through an active process of interacting with others in a particular social context and in the process, society imposes its conception of what it considers appropriate for the individual based on his or her sex category (Alhassan, 2012). Finally, the spouses were framed as more forthright, more outspoken, and more provocative, at times appearing as the spokespersons for their respective parties (Zeldes, 2009).

\section{Conclusion}

The core findings of this study showed that the female spouses of the presidential candidates were framed with more attention given partisan political participation and where they stood on policy issues than about personal attributes. The study also showed that in relation to policy issues, the spouses were portrayed as sharing views on what was regarded as both 'feminine'(healthcare) and 'masculine'(economy, governance). Again, the female spouses were largely seen and heard as supporting their husbands, a trend that indicated a deviation from what is known to be the norm or traditional role of presidential candidates' spouses being just 'escorts' trailing along with their husbands as they embark on rallies and campaign (Zeldes, 2009).

However, gender played a significant role in the framing of news on the female spouses of the presidential candidates. It was evident from the study and corroborated by findings from existing studies that the framing of spouses of presidential candidates is gender-centric. Essentially, each of the dominant frames was laced with elements of gender as the spouses were framed as breaking, subverting or affirming stereotypes positioning. Consequently, if gender equality is to be achieved in politics, gender disparity in news must be addressed. For instance, to provide more opportunities for women to enter politics, advocates frequently argue that we need to "level the playing field" (Carroll \& Fox, 2006).

Another noticeable finding relates to the influence culture and social constructs had on the media's construction and framing of these female spouses. In short, when we consider the public, the language, the expectations, and the strategies of contemporary politics, we realise that gender plays an important role in elections. Even when gender is not explicitly acknowledged, it often operates in the background, affecting our assumptions about who are the legitimate political actors and how they should behave. Therefore, there is the need to improve 
or change several issues for women to wholly benefit from the emerging trends in political participation. These include transforming the patriarchal and religious beliefs; intensifying capacity building and enhancement programmes to boost women's participation in politics; and, providing positive media coverage for female actors and participants in the politics (Ndlovu \& Mutale, 2013).

\section{REFERENCES}

Affum, V. (1998).Emerging gender roles in the Ghanaian society and its implications for district development planning: A case study of the Bosomtwi-AtwimaKwanwom district. (Unpublished Master's Thesis, Kwame Nkrumah University of Scienceand Technology) Retrieved from http://ir.knust.edu.gh/xmlui/handle/123456789/2975?show=full

Alhassan, S. N. (2012). Language and gender: the construction and reproduction of gender in Dagbanli. (Unpublished Doctoral Dissertation, University of Ghana, Legon).Retrieved from http://ugspace.ug.edu.gh/.

Allah-Mensah, B. (2005). Women in Politics and Public Life in Ghana. Accra, Ghana: Friedrich Ebert-Foundation.

Amevor, E. (2014). Newspapers' framing of presidential candidates in Ghana's 2012 general elections.(Unpublished Master's Thesis, University of Education, Winneba).

Atkeson, L. R. \& Krebs, T. B. (2008). Press Coverage of Mayoral Candidates: The Role of Gender in News Reporting and Campaign Issue Speech. Political Research Quarterly, 61 (2), 239-252.

Azanu, B. (2012). Media framing of women in political and non-political spaces: an analysis of how newspapers framed women leaders in Ghana from 2009-2010. (Unpublished Master's thesis, University of Education, Winneba).

Berger, P. L., \& Luckmann, T. (1991). The social construction of reality: A treatise in the sociology of knowledge (No. 10). UK, Penguin.

Bowen, G. A. (2009). Document analysis as a qualitative research method. Qualitative research journal, $9(2), 27-$ 40.

Braimah, R. (2015). A phenomenological study of selected public relations agencies in Ghana.(Unpublished Master's Thesis, University of Education, Winneba).

Butler, J. (1999). Gender trouble: Feminism and the subversion of identity (10th ed). London, UK: Routledge.

Bystrom, D., \& Dimitrova, D. V. (2013). Migraines, marriage, and mascara: Media coverage of Michele Bachmann in the 2012 Republican Presidential Campaign. American Behavioral Scientist, 58(9), 1169-1182.

Carroll, J. (2008). A place through my eyes a social constructionist approach to researching the relationship between socio-economic living contexts and physical activity. (Unpublished Doctoral Dissertation, Queensland University of Technology).Retrieved from https://eprints.qut.edu.au/27965/2/JulieAnne_Carroll_Thesis.pdf.

Carroll, S. J., \& Fox, R. L. (2006). Introduction: gender and electoral politics into the twenty-first century. Gender and Elections: Shaping the Future of American Politics, 1-11.

Chong, D., \&Druckman, J. N. (2007).Framing theory. Annu. Rev. Polit. Sci., 10, 103-126.

Crabb, P. B., \&Bielawski, D. (1994).The social representation of material culture and gender in children's books. Sex roles, 30(1-2), 69-79.

Daymon, C. \& Holloway, I. (2005).Qualitative Research Methods in Public Relations and Marketing Communications. London: Routledge.

de Vreese, C. H. (2004). The effects of frames in political television news on issue interpretation and frame salience. Journalism \& Mass Communication Quarterly, 81(1), 36-52.

de Vreese, C. H. (2005). News framing: Theory and typology. Information Design Journal \& Document Design, 13(1), 51-62. Retrieved from https://msapunlam.ac.id/download/bahan_bacaan/New\%20Framing.pdf

Denzin, N. K., \& Lincoln, Y. S. (Eds.). (2011). The Sage handbook of qualitative research. Los Angeles: Sage.

Denzin, N.K. \& Lincoln, Y.S. (2007). Introduction: The Discipline and Practice of Qualitative Research: The Landscape of Qualitative Research. In The Sage handbook of qualitative research (1-43). Los Angeles: Sage

Edelman, M. (1993).Contestable categories and public opinion. Political communication, 10(3), 231-242.

Entman, R. M. (1993a). Framing U. S coverage of international news: contrasts in narratives of KAL and Iran Air incidents. Journal of Communication, 41,(4): 52.

Entman, R. M. (1993b). Framing: toward clarification of a fractured paradigm. Journal of Communication 43(4).Retrieved from: https://www.unc.edu/ fbaum/teaching/articles/J-Communication-1993-Entman.

Gamson, W., \& Modigliani, A. (1989). Media discourse and public opinion on nuclear power: A constructionist approach. American Journal of Sociology, 95, (1), 1-37.

GeoPoll (2018). Ghana Media Measurement Report: Top TV, Radio and Print Outlets in 2018. Retrieved from: https://www.geopoll.com/blog/ghana-media-measurement-report-top-tv-radio-print-outlets-2018

Global Security's Ghana- Political Parties. (n.d.). Retrieved from Global Security website:https://www.globalsecurity.org/military/world/africa/gh-political-parties.htm 
Goffman, E. (1974). Frame analysis: an essay on the organization of experience. Cambridge, MA: Harvard University Press.

Handrahan, L. (2004). Conflict, gender, ethnicity and post-conflict reconstruction. Security Dialogue, 35(4), 429445.

Iwashita, C. (2003). Media construction of Britain as a destination for Japanese tourists: Social constructionism and tourism. Tourism and Hospitality Research, 4(4), 331-340.

Janus, M. J (2008).Gender Roles, Leadership and Public Relations.(Master's Thesis, University of MissouriColumbia).

Kessler, S. J., \& McKenna, W. (1978). Gender: An ethnomethodological approach. University of Chicago Press.

Kiwanuka-Tondo, J., Albada, K. F., \& Payton, F. C. (2012). Media ownership and news framing: an analysis of HIV/AIDS coverage by Ugandan press. African Journal of AIDS research, 11(4), 361-371.

Krook, M. L. (2010). Why are fewer women than men elected? Gender and the dynamics of candidate selection.Political Studies Review: 8, 155-168. DOI: 10.1111/j.1478-9302.2009.00185.

Lindlof, T.R. \& Taylor, B.C. (2002).Qualitative Communication Research Methods $-\left(2^{\text {nd }}\right.$ Ed.).SAGE Publications, Inc.

Lorber, J. (1993). Believing is seeing: Biology as ideology. Gender \& Society, 7(4), 568-581.

Lorber, J. (1994). "Night to his Day": The Social Construction of Gender. Yale University Press.

Ndlovu, S., \& Mutale, S. B. (2013).Emerging trends in women's participation in politics in Research Methods.(2 ${ }^{\text {nd }}$ ed.). Boston: Allyn \& Bacon

Ofori-Birikorang, A. (2018)News construction on the pivots of framing and ideology: A theoretical perspective. Research on Humanities and Social Sciences, Vol. 9. No. 2 ISSN 2224-5766 (Paper) ISSN 2225-0484 (Online) DOI: $10.7176 /$ RHSS

Ofori-Birikorang, A. (2009). Promoting a new health policy in the Ghanaian media: Newspaper framing of the National Health Insurance scheme from 2005-2007. (Doctoral Dissertation, Ohio University).

Oyesomi, K. O., \&Oyero, O. (2012).Newspaper Coverage of Women's Participation in the 2011 General Elections in Nigeria. The Nigerian Journal of Communication, 10(1), 136-156.

Rek, B., \& Murphy, J. (2016).Candidate gender and the quantity of media coverage in the 2015 general election.Retrieved https://www.psa.ac.uk/sites/default/files/conference/papers/2016/Rek_Murphy_Gender_0.pdf.

Ryan, K. (2013). The media's war on women: Gendered coverage of female candidates. Xavier University www.xavier. edu/xjop/documents/xjopvol4/no, 1 .

Sanders, J. (2000) South Africa and the international media, 1972-1979: A struggle for representation. London: Frank Cass publishers.

Tewksbury, D., \&Scheufele, D. A. (2007). Special issue on framing, agenda setting, \& priming: Agendas for theory and research. Journal of Communication, 57(1), 8-8.

Top sites in Ghana (2016).Retrieved from http://www.alexa.com/topsItes/countries/GH.

Uscinski, J. E., \& Goren, L. J. (2011). What's in a Name? Coverage of Senator Hillary Clinton during the 2008 Democratic Primary.Political Research Quarterly, 64 (4), 884 -896.

Wasburn, P. C., \& Wasburn, M. H. (2011). Media coverage of women in politics: The curious case of Sarah Palin. Media, Culture \& Society, 33(7), 1027-1041.

West, C., \& Zimmerman, D. H. (1987).Doing gender. Gender \& society, 1(2), 125-

151.

Westbrook, L., \& Schilt, K. (2014).Doing gender, determining gender: Transgender people, gender panics, and the maintenance of the sex/gender/sexuality system. Gender \& Society, 28(1), 32-57.

Wilde, K. (2015). Women in Sport: Gender stereotypes in the past and present. Retrieved February, 4, 2015.

Winfield, B. H., \& Friedman, B. (2003). Gender politics: news coverage of the candidates' spouses in campaign 2000. Journalism \& Mass Communication Quarterly, 80, 548-566.

Zeldes, G. A. (2009). Maverick, escort, or style setter - TV news framing of candidates' spouses during the 2004 and 2008 presidential elections TV news framing the candidates' spouses. Electronic News, 3 (4), $193-213$. DOI: $10.1080 / 19312430903300012$

\section{AUTHORS}

Yvonne Dedzo is an Assistant Lecturer in the Department of Communication and Media Studies, University of Education, Winneba. Her areas of research include Gender and Media, Discourse analysis, Popular Culture and Communication Skills Study.

Andy Ofori-Birikorang is an Associate Professor in the Department of Communication and Media Studies at the University of Education Winneba. His areas of research include communication and critical pedagogy, popular culture and African media, gender and media, media theories, development communication, health communication as well as social media and identity research. 